\title{
APLIKASI E-LEARNING SENI BUDAYA BERBASIS ANDROID MENGGUNAKAN TEKNOLOGI PHONEGAP PADA SMK NEGERI 1 DEPOK
}

\author{
Sri Melati Sagita ${ }^{1}$, Rini Amalia ${ }^{2}$ \\ Program Studi Informatika, Universitas Indraprasta PGRI \\ 61tamelati2013@gmail.com¹, reen amaleea@yahoo.com²
}

\begin{abstract}
Abstrak
Konsep e-learning membawa pengaruh terjadinya perpindahan pendidikan konvensional menjadi bentuk digital, baik secara isi dan sistemnya. SMK N 1 Depok dalam proses pembelajaran masih bersifat konvensional, dimana proses belajar mengajar terlaksana dengan syarat pertemuan antara siswa dan guru di dalam kelas. Proses pembelajaran dapat terhambat jika pertemuan tidak ada. Sehingga menghambat proses pembelajaran di SMK N 1 Depok yang berakibat berkurangnya pemahaman siswa pada suatu mata pelajaran. Mengembangkan e-learning berbasis android dengan menggunakan tekonologi phonegap diharapkan kualitas pembelajaran dan hasil belajar diharapkan akan semakin baik.Aplikasi e-learning ini memberikan kemudahan kepada pengguna (siswa) untuk mendapatkan materi pelajaran Seni Budaya dalam bentuk teori, gambar dan video.Di dalam aplikasi ini juga terdapat latihan soal yang dapat dikerjakan oleh siswa dan hasil dari pekerjaan mereka dapat dilihat langsung. Aplikasi ini dapat memberikan kemudahan bagi para penggunanya sehingga tidak perlu bersusah payah membawa buku yang relative tidak efektif. Dengan hanya membuka aplikasi ini pada ponsel Android, informasi mengenai materi pelajaran Seni Budaya sudah bisa didapatkan dengan mudah.
\end{abstract}

Kata Kunci :E-Learning, Android, phonegap

\begin{abstract}
The concept of e-learning brings the impact of the conventional transfer of education into a digital form, both in content and system. SMK N 1 Depok in the learning process is still conventional, where the learning process is done with the condition of meeting between students and teachers in the classroom. The learning process can be hampered if the meeting does not exist. thus hampering the learning process in SMK N 1 Depok which resulted in less understanding of students on a subject. Developing android-based e-learning using phonegap technology is expected to improve the quality of learning and learning outcomes. This elearning application provides convenience to the users (students) to get the subject matter of Art Culture in the form of theory, pictures and video. In this application there is also a workout problem that can be done by students and the results of their work can be seen directly. This application can provide convenience for its users so no need to bother to bring a book that is relatively ineffective. By simply opening this app on your Android phone, information about Art Culture lesson material can be obtained easily.
\end{abstract}

KeyWords:E-Learning, Android, phonegap

\section{PENDAHULUAN}

Seiring dengan perkembangan teknologi informasi yang semakin pesat, kebutuhan akan suatu konsep dan mekanisme belajar e-learning mengajar berbasis TI menjadi tidak terelakkan lagi. Konsep dengan sebutan e-learning ini membawa pengaruh terjadinya perpindahan pendidikan konvensional menjadi bentuk digital, baik secara isi dan sistemnya. Saat 
ini e-learning telah diterima oleh masyarakat dunia, terbukti dengan maraknya implementasi pada pendidikan maupun industri.

SMK N 1 Depok dalam proses pembelajaran masih bersifat konvensional, dengan kata lain proses belajar mengajar antara siswa dan guru hanya dapat dilakukan dengan syarat terjadinya pertemuan antara siswa dan guru di dalam kelas. Jika pertemuan siswa dan guru tidak terjadi maka secara otomatis proses pembelajaran pun tidak dapat dilaksanakan. Selain itu, pendidikan ilmu pengetahuan hampir sepenuhnya dilakukan di dalam kelas yang menyebabkan proses pembelajaran dapat terhambat jika pertemuan tidak ada. Keadaan seperti ini sangat jelas dapat menghambat proses pembelajaran di SMK N 1 Depok yang berakibat berkurangnya pemahaman siswa pada suatu mata pelajaran. Maka dari itu, perlu dibuat suatu aplikasi e-learning berbasis Android yang dapat diakses dimana saja dan kapan saja sehingga mendukung pendidikan serta mempermudah dalam penyebaran ilmu pengetahuan kepada siswa SMK N 1 Depok.

E-learning merupakan media teknologi informasi yang memiliki kemampuan untuk mengembangkan aplikasi proses belajar mengajar. Selain itu, Komisi Eropa mendefinisikan E-learning sebagai penggunaan teknologi multimedia baru dan internet untuk meningkatkan kualitas pembelajaran dengan memfasilitasi akses ke sumber daya dan jasa provider dalam menyediakan kapasitas sesuai Kebutuhan [1]. Dari uraian-uraian diatas maka penulis memutuskan untuk mengangkat judul "Aplikasi E-Learning Seni Budaya Pada Smartphone Berbasis Android Menggunakan Teknologi Phonegap Sebagai Media Pembelajaran Pada SMK Negeri 1 Depok".
Penelitian ini bertujuan untuk memberikan dukungan dalam proses pembelajaran dan membantu Guru Seni Budaya dan Siswa/i SMK N 1 Depok memperoleh informasi yang dapat diakses dimana saja dan kapan saja sehingga mendukung pendidikan serta mempermudah dalam penyebaran ilmu pengetahuan kepada siswa/i SMK N 1 Depok. Bagi guru bermanfaat sebagai alternatif media pembelajaran dalam kegiatan belajar mata pelajaran seni budaya dan membantu guru seni budaya dalam memberikan materi pelajaran di SMK N 1 Depok menjadi lebih menarik.

\section{METODE PENELITIAN}

\section{A. Metode Pengumpulan Data}

Pada penelitian ini teknik pengumpulan data yang dilakukan oleh penulis yaitu dengan dua cara yakni observasi dan wawancara.

1) Observasi

Sebagai langkah awal yang dilakukan oleh penulis adalah observasi pada SMA N 1 Depok untuk mengetahui secara langsung permasalahanpermasalahan yang harus diteliti. Observasi menjadi suatu keuntungan bagi penulis dalam mengumpulkan data karena dari observasi penulis dapat melihat secara langsung bagaimana permasalahan-permasalahan yang sedang terjadi.

2) Wawancara

Selain melakukan observasi penulis juga melakukan wawancara. Dengan wawancara penulis dapat menanyakan secara langsung permasalahanpermasalahan yang terjadi sehingga penulis dapat mengetahui secara rinci bagaimana keadaan yang sesungguhnya dan penulis dapat menanyakan beberapa hal kegiatan khusus yang tidak selalu terjadi. 


\section{B. Analisis dan Perancangan}

\section{Analisis Prosedur Kerja}

Berdasarkan pengamatan penulis di SMK Negeri 1 Depok pada saat ini proses belajar mengajar yang dilakukan masih dengan system konvensial. Dimana system belajar mengajar dapat terjadi apabila di dalam kelas terdapat guru dan murid yang saling berinteraksi, begitu juga dengan system belajar mengajar pada mata pelajaran seni budaya. Sistem ini mempunyai kendala, dimana jika seorang guru tidak hadir maka tidak dapat terjadi belajar mengajar. Sehingga potensi terjadinya jam kosong sangat besar, dan hal seperti ini dapat menyebabkan kurangnya jam pelajaran sehingga banyak pelajaran seni budaya yang ditinggalkan. Untuk itu penulis menemukan alternative dalam menyelesaikan permasalahan diatas, penggunaan e-learning seni budaya dengan bantuan teknologi Phonegap sebagai alat untuk menghubungkan file HTML, Java Script dan CSS ke Java Android dalam pembuatan aplikasi sederhana berbasis Android untuk memberikan cara lain atau media belajar mengajar tambahan yang baru [2]. Tentu saja aplikasi ini dibuat dengan harapan supaya pelajaran-pelajaran yang tertinggal dapat disampaikan melalu e-learning Seni Budaya ini sehingga memperoleh hasil belajar mengajar yang maksimal dan berkualitas.

2. Analisis Perancangan Sistem

Teknik analisis yang digunakan pada penelitian ini menggunakan pendekatan Object Oriented Analysis (OOA) atau analisis berorientasi obyek dengan UML. Proses analisis dilakukan terhadap hasil tahapan pengumpulan data dengan wawancara, observasi, dan studi pustaka untuk mendapatkan spesifikasi kebutuhan sistem yang akan dikembangkan.
Pada proses analisis, teknik analisis yang dilakukan adalah:

a. Analisis Data dan Informasi Sistem Berjalan, Analisis dilakukan terhadap prosedur, dokumen, file dan hasil cetakan dari sistem yang sudah berjalan.

b. Analisis Kebutuhan Fungsional dan Non-Fungsional. Pemodelan kebutuhan fungsional dilakukan dengan Use Case Diagram.

c. Analisis Perilaku Sistem. Pada tahapan ini, dilakukan analisis perilaku sistem yang dikembangkan dan dimodelkan dengan Activity Diagram dan Sequence Diagram.

3. Teknik Perancangan Sistem

Teknik perancangan sistem yang digunakan pada penelitian ini menggunakan Perancangan Berorientasi Obyek menggunakan Unified Modelling Language (UML). Pada proses perancangan, teknik perancangan yang dilakukan adalah:

a. Perancangan program atau spesifikasi sistem, yang dimodelkan dengan Class Diagram.

b. Perancangan Database. data apa yang disimpan, format data yang digunakan, dimana data akan disimpan Database design (ER diagram).

c. Perancangan Antarmuka Pengguna (Navigasi, form Input, form Output),

d. Perancangan Infrastructure Architecture (hardware, software, dan network) [3]. 
4. Bagan Alir Penelitian

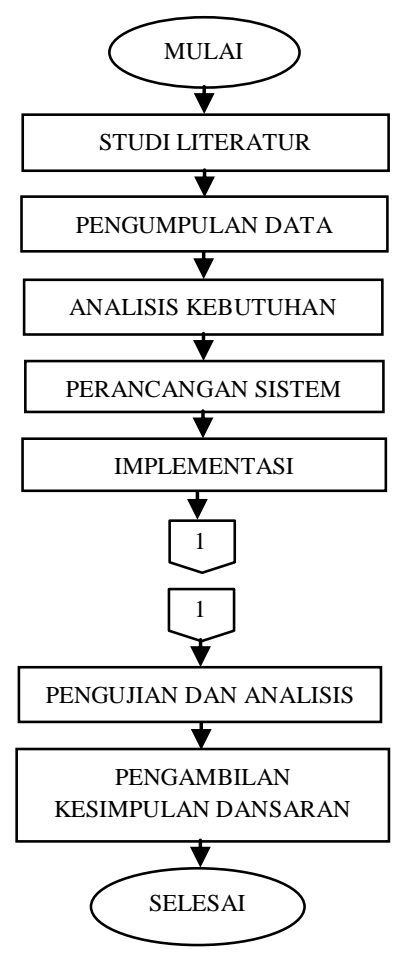

Gambar 1. Bagan Alir Penelitian

\section{HASIL DAN PEMBAHASAN}

\section{A. Perancangan dan Implementasi}

Menu Utama pada program ini adalah "Mulai" dan "Keluar". Pembuatan program ini dikerjakan dengan beberapa tahap, yang pertama adalah perancangan UML (Unified Modeling Language, yaitu memodelkan sistem yang dibuat. Langkah pembuatan aplikasi yaitu membangun kode program. Dilanjutkan dengan pembuatan antarmuka beserta program logikanya. Kemudian tahap implementasi program.

Pemodelan aplikasi ini menggunakan UML sebagai pemodelan sistemnya. UML yang digunakan dan perancangan aplikasi ini yaitu Use Case Diagram, Activity Diagram, Sequence Diagram dan Class Diagram.
1. Use Case Diagram

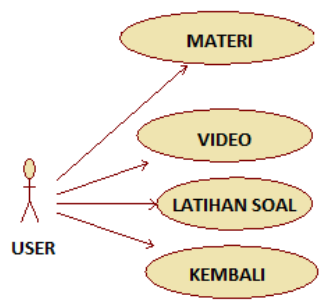

\section{Gambar 2. Use Case Diagram}

2. Rancangan Tampilan Aplikasi

Rancangan tampilan aplikasi ini terdiri dari perancangan halaman tampilan awal, perancangan tampilan didalam button masuk yang menampilkan pilihan menu, rancangan halaman materi dan informasinya menampilkan materi pelajaran Seni Budaya, perancangan halaman video, perancangan halaman untuk latihan soal, dan rancangan halaman hasil untuk menampilkan nilai dari latihan soal yang sudah dikerjakan siswa.

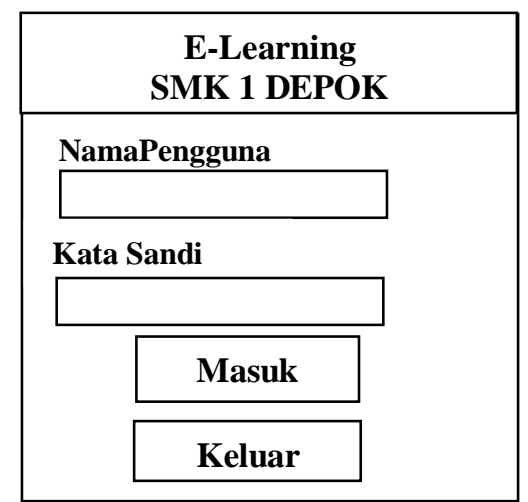

Gambar 3. Rancangan Halaman Awal

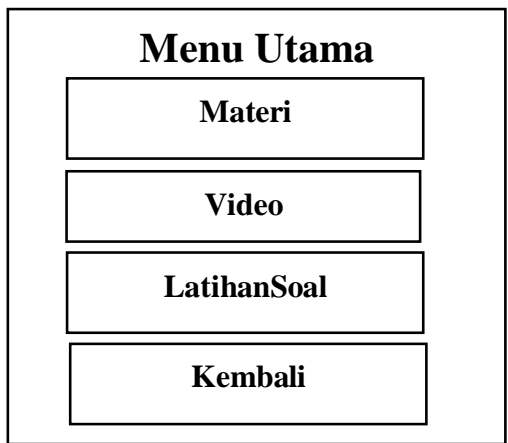

Gambar 4. Rancangan Halaman 


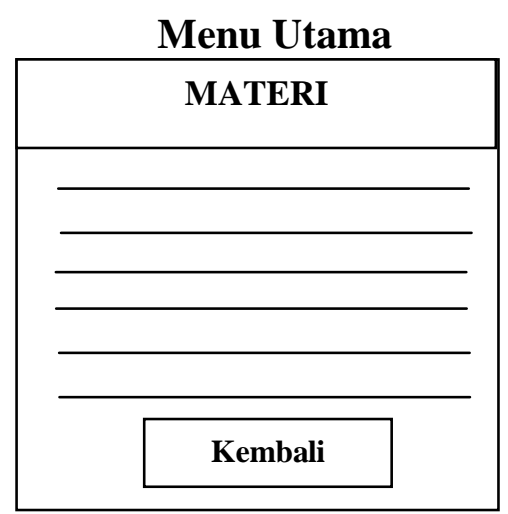

Gambar 5. Rancangan Halaman Materi

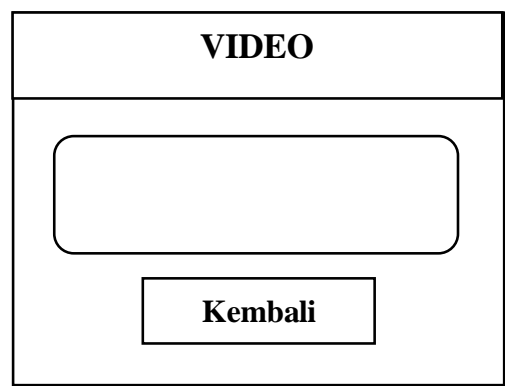

Gambar 6. Rancangan Halaman Video

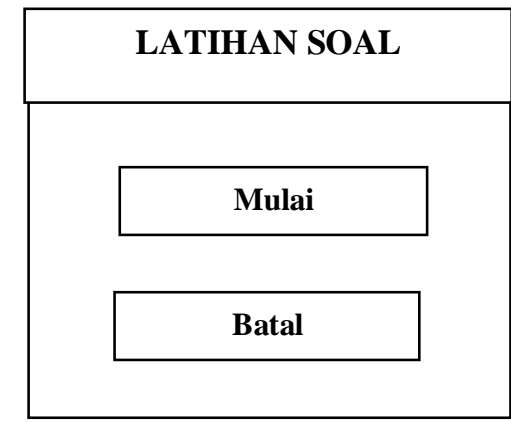
Gambar 7. Rancangan Halaman
Latihan Soal

\begin{tabular}{|l|}
\hline \multicolumn{1}{|c|}{ HASIL } \\
\hline Jumlahbenar \\
Nilai Total \\
\hline KembaliKe Menu Utama \\
\hline
\end{tabular}

Gambar 8. Rancangan Halaman Hasil

\section{B. Pengujian Aplikasi \\ E-Learning \\ SMK 1 DEPOK}

Nama Pengguna

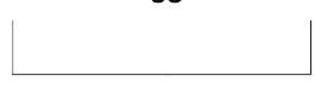

Kata Sandi

\section{Masuk}

\section{Keluar}

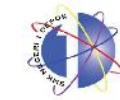

\section{Gambar 9. Tampilan Halaman Awal}

Pada tampilan halaman awal, pengguna diminta untuk memasukan nama pengguna dan kata sandi. Ada dua pilihan tombol MASUK untuk masuk ke Menu berikutnya atau Tombol KELUAR untuk keluar aplikasi.

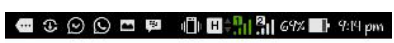

\section{MENU UTAMA}

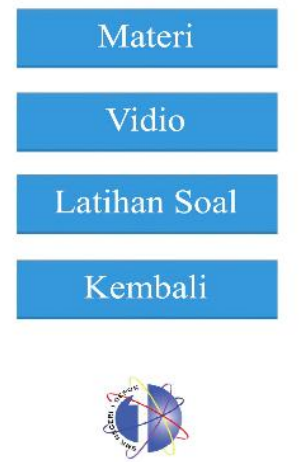

\section{Gambar 10. Tampilan Halaman Utama}

Didalam tampilan halaman utama terdapat 4 tombol yaitu tombol Materi, tombol Video, tombol Latihan Soal dan tombol Kembali. Tombol Materi, Video, Latihan Soal akan masuk ke Sri Melati Sagita, Aplikasi E-Learning Seni ... 
halaman berikutnya sedangkan tombol Kembali untuk kembali ke halaman sebelumnya.

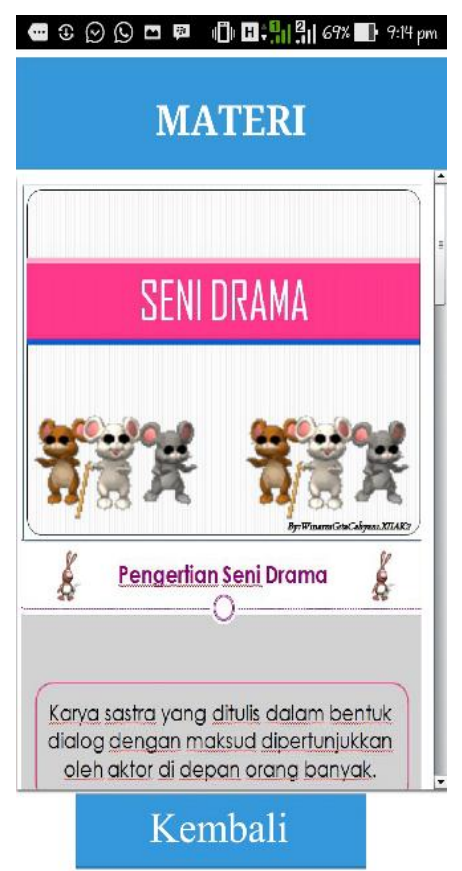

\section{Gambar 11. Tampilan Halaman Materi}

Pada tampilan halaman materi berisi materi seni budaya yang merupakan materi mata pelajaran seni budaya pada SMKN 1 Depok.
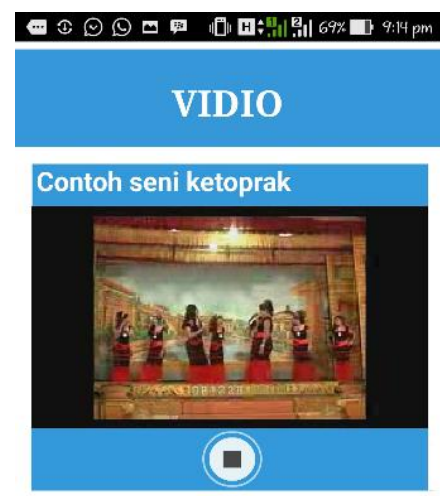

\section{Kembali}

\section{Gambar 12. Tampilan Halaman Video}

Tampilan halaman video berisi videovideo yang berhubungan dengan seni budaya yang ada di Indonesia. Contoh video adalah seni ketropak di Indonesia.

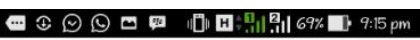

\section{LATIHAN SOAL}

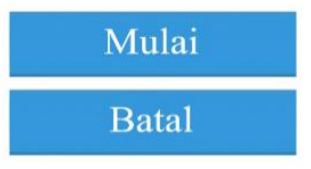

\section{Gambar 13. Tampilan Halaman Latihan Soal}

Pada halaman latihan soal, murid SMKN 1 Depok dapat melakukan latihan soal mata pelajaran seni budaya. Di dalam tampilan terdiri dari dua tombol yaitu Mulai untuk memulai latihan soal dan tombol Batal untuk membatalkan pengerjaan latihan soal.
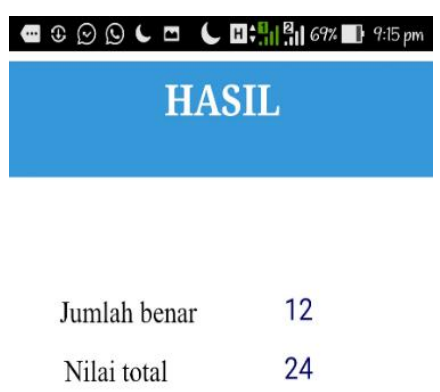

\section{Kembali ke}

menu utama

\section{Gambar 14. Tampilan Halaman}

Sri Melati Sagita, Aplikasi E-Learning Seni ... 


\section{Hasil}

Pada tampilan halaman hasil adalah hasil dari pengerjaan latihan soal. Akan ditampilkan berapa jumlah soal yang benar dan berapa soal yang salah. Didalam tampilan halaman hasil tedapat tombol kembali ke menu utama.

\section{SIMPULAN}

Aplikasi E-Learning Seni Budaya Pada Smartphone Berbasis Android Menggunakan Teknologi Phonegap Sebagai Media Pembelajaran Pada SMK Negeri 1 Depok dibuat menggunakan phonegap. PhoneGap ini merupakan sebuah framework yang menjembatani kebutuhan web apps developer. PhoneGap mempunyai banyak library JavaScript dihubungkan dengan dukungan tag-tag HTML5. PhoneGap tidak hanya mendukung Android OS, tetapi juga platform-platform lain seperti Symbian, iOS, Bada, WebOS, dan Windows Phone, tentu dengan penyesuaian SDK masingmasing, aplikasi ini telah diterapkan pada ponsel bersistem operasi Android versi 4.0 (Ice Cream Sandwich) dengan tipe ponsel Smartfreen Andromax U.

Aplikasi ini memberikan kemudahan kepada pengguna (siswa) untuk mendapatkan materi pelajaran Seni Budaya dalam bentuk teori, gambar dan video. Di dalam aplikasi ini juga terdapat latihan soal yang dapat dikerjakan oleh siswa dan hasil dari pekerjaan mereka dapat dilihat langsung. Aplikasi ini dapat memberikan kemudahan bagi para penggunanya sehingga tidak perlu bersusah payah membawa buku yang relative tidak efektif. Dengan hanya membuka aplikasi ini pada ponsel Android, informasi mengenai materi pelajaran Seni Budaya sudah bisa didapatkan dengan mudah.

\section{UCAPAN TERIMA KASIH}

Terima kasih kepada Lembaga Penelitian dan Pengabdian Masyarakat Universitas Indraprasta PGRI yang telah membantu kegiatan penelitian ini dengan Kontrak Program Penelitian Nomor: 1212/SP3M/KP/UNINDRA/X/2016

\section{DAFTAR PUSTAKA}

[1] S. Nagwa A., "Using E-Learning to Develop EFL Students'Language Skills and Activate Their Independent Learning", Creative Education, Vol. 5, 2014, pp. 752-757

[2] Hermawan, Stephanus. (2011). Mudah Membuat Aplikasi Android. Jakarta : Andi Publiser.

[3] Jogiyanto HM., MBA., Akt., Ph.D. (2010). Analisis dan Desain Sistem Informasi. Yogyakarta : Andi

[4] Safaat, Nazruddin. (2011). Pemrograman Aplikasi Mobile Smartphone dan Tablet PC Berbasis Android. andung :Informatika.

[5] Supardi, Yanuari. (2011). Semua Bisa Menjadi Programer Android Basic.Jakarta : Elex Media Komputindo 